\title{
Roundtable
}

\section{Response to Wilkinson \& Tepfer's “Fitness and beyond: preparing for the arrival of GM crops with ecologically important novel characters"}

\author{
Detlef BARTSCH* \\ Federal Office for Consumer Protection and Food Safety, Mauerstrasse 39-42, 10117 Berlin, Germany
}

Keywords: weediness / fitness / GM crop / environmental risk assessment

Mike Wilkinson and Mark Tepfer's commentary (Wilkinson and Tepfer, 2009) is a very welcomed contribution towards more realism in environmental risk assessment (ERA). I share most of their views regarding the next generation of GM crops with ecologically important novel characters. Looking at the past GM crops with herbicide tolerance and insect resistance traits, one must confess that environmental impacts reported so far are - if at all - small compared to other consequences of human activities (e.g. global climatic change or increased salinization of cropland).

However, the quantification of 'fitness' is not an easy task, as this term clearly depends on the environmental context (e.g. the novel plant in the receiving environment). I know colleagues who recommend measuring 'plant performance' instead of 'fitness'. Then the impact of novel genetically modified characters on the establishment and spread in the context of the receiving environment is a key point. Two considerations will strengthen the regulatory preparation for novel characters: (1) assessing the ecological phenotype and (2) definition of 'weediness'.

\section{ASSESSING THE ECOLOGICAL PHENOTYPE}

In ecological sciences, it is the phenotype that counts. If foreign genes are added to a plant genome, the resulting phenotype will determine potential ecological interactions, not the genotype as such. For example, tolerance to salinity is one of the determining factors controlling the establishment of plants in salt marsh and salt desert environments. Competition is hypothesized to play a key role in determining both the upper and lower limits of

* Corresponding author: detlef.bartsch@bvl.bund.de species distribution along a salinity gradient. The relationship between the level of salt tolerance of species and their ability to compete with glycophytes in less saline habitats seems to be reciprocal. Halophytes - sugar beet is a good example - are not competitive in non-saline habitats. Their competitiveness would increase in saline habitats like seashores if novel characters would enhance salt tolerance. From this I conclude that future ERA of GM plants can - more than it is currently the case be performed based on knowledge derived from conventional and already existing GM plants, e.g. with characters like enhanced salt tolerance.

\section{DEVELOPMENT OF COMMON REGULATORY AGREEMENT ON THE 'WEEDINESS' CONCEPT}

Popular as well as subjective concepts define weeds as plants of any kind growing in the wrong place, causing damage by aggressive behavior, being of no benefit and suppressing cultivated plant species. Economical weed concepts reflect the view of agronomists who concentrate on the reduction of yield, thereby stressing the damage aspect. A weed problem is solved as soon as the plant no longer creates considerable damage in the fields, a state which is reached by means of appropriate weed control (crop rotation, tillage, herbicide application). In contrast to the concept mentioned above, ecological definitions include habitats outside agrosystems colonized by weeds. The usual preference of weeds for habitats disturbed by man is stressed, like for cultivated fields and gardens, as well as disturbed areas on road sides, recently built artificial slopes and others. An aggressive weed can cause damage not only in agrosystems but also in (semi-) natural plant communities by out-competing weak species. It is sometimes difficult to call a plant 
a weed because one and the same species may be considered in some parts of its area as a harmless component of natural vegetation, in others as a weed, and again in others even as a useful plant species. Traditional breeding has so far focused on biomass improvement efforts. In comparison to wild relatives, cultivars are in general genetically less diverse, e.g. due to selection for homogeneity, and therefore are often less adapted to competition in natural environments. Reports of fitness enhancement for crop-wild hybrids in natural ecosystems are rare. To the contrary, hybridization and introgression of cultivar genes has led to disadvantages for wild plant populations in some documented cases, but not always. Thus, in a few cases, crop-to-weed gene flow has had important practical and economic consequences since it promoted the evolution of more aggressive weeds. In addition, one of the most important goals is the conservation of plant genetic resources, in this case the genetic diversity of wild relatives of crop plants. If a foreign transgenic trait offers additional ecological advantages for establishment and spread, such that the resulting crop becomes a weed, the ecological consequences of introduction could be serious.
Public-sector research must take part in the development of a reliable and workable ERA. Unfortunately I have not seen too many attempts to establish the necessary infrastructure at universities or public research institutions, and instead public funding seems to have decreased in the last few years. One important reason might be that knowledge generated by public-sector research has often not altered the heavy political debate on the pros and cons of GM crops. Too many stakeholders are trapped in societal constraints and prejudices, expressed by slogans like: "I have my opinion, don't disturb me by facts". Anyhow, I strongly believe that science-based decision making is the best way to solve problems arising from human activities.

Received February 22, 2009; accepted February 26, 2009.

\section{REFERENCES}

Wilkinson M, Tepfer M (2009) Fitness and beyond: preparing for the arrival of GM crops with ecologically important novel characters. Environ. Biosafety Res. 8: 1-14 